\title{
A SURVEY ON 5G: TECHNOLOGY AT THE DOORSTOP
}

\author{
Naheed Nazneen Tuli \\ Department of IT \\ East West University, Dhaka, Bangladesh
}

\author{
Mohammad Arifuzzaman \\ Department of IT \\ East West University, Dhaka, Bangladesh
}

\begin{abstract}
A This paper surveys the "Five Disruptive Technology Directions for 5G" [1] and being heterogeneous to earlier surveys, shows the vision of 5G which includes the key technological aspects as well as the trial and migration plan. For each proposed conceptual architecture of 5G, we provide a comprehensive presentation of the concept, a discussion on the enhancements and variants on that concept, and a detailed picture of the latest state-of-the-art technology of that architecture. The objective of this study is to provide the big picture of $5 \mathrm{G}$ while simultaneously focus on the details of development of the technology (both theory and practice) and their feasibility for adopting in near future. We believe that this organization of works sheds some light on the design choices of $5 \mathrm{G}$, clarify design goals for focusing design parameters of interest to communication engineers, essentially enabling the design and implementation of more reliable, robust and efficient 5G solutions.
\end{abstract}

Keywords - 5g, slicing architecture, implementation, standardization activities

\section{INTRODUCTION}

According to Mobile and wireless communications Enablers for the Twenty-twenty Information Society (METIS) [2], the fundamental criteria of $5 \mathrm{G}$ networks are as follows: 1) "Amazingly fast" 2) "Great service in a crowd" 3) "Ubiquitous things communicating" 4) "Best experience follows you" 5) "Super real-time and reliable connections". The network will be densified with 10-100 times number of devices, 1000 times more data volume, 10-100 times high data rate, it should have 10 times longer battery life and 5 times reduced end to end (E2E) latency.5G networks are at our doorstep waiting for us to embrace it. Already various project and research works are being made to make a clear understanding of the feasibility of 5G infrastructure. Although many research topics and limitations still need to be covered with real time data, we yearn to achieve it by 2020 . European Telecommunications Standards Institute's (ETSI's) Framework 7 works with projects like 5GNOW [3] and METIS that looks for new waveforms and the basic properties to meet $5 \mathrm{G}$ requirements in 2020.The increased number of users and devices connected to the internet worldwide has a vast impact on our economy as well. According to European Mobile Observatory (EMO), in 2010 the mobile communication sector had total revenue of $€ 174$ billion exceeding the sectors of aerospace and pharmaceutical sectors [4].

We take into consideration "Five Disruptive Technology Directions for 5G'[1] as a visionary paper for our work.It is seen; the authors focus on 5 main criteria to define the $5 \mathrm{G}$ future networks: 1) Device-centric architecture, 2) Millimeter wave (mmwave), 3) Massive MIMO, 4) Smarter Devices and 5) Machine-to-machine communication. We endeavor to explore how much of these are actually being researched or applied in real life. A total of six revolutionary papers are selected from the year of 2014 and discussed in the following section.In [5], the critical condition of our environment due to carbon dioxide emission and rise in sea level, and huge consumption of energy leads us to become green and soft. As the traffic load and number of connected devices increases, network densification results [6]which includes spatial densification, neighboring small cell(NSC), device to device communication. In [3], some crucial results are mentioned from the European research project such as the change in basic system for the introduction of Internet of Things, etc. It also includes the advantages of non-orthogonal, asynchronous waveforms. An architecture is proposed in [4] to differ the indoor and outdoor communication, visible light communication and many more. Many of the features such as ultra-densification, mmWave, and massive multiple-input multiple-output (MIMO) are described broadly in [7]. As stated in [8], the importance of virtual zero latency and high data rate usage should be available to users and machines whenever and wherever they are. Nokia is already involved in research activities with METIS, ITU-R, China IMT-2020 and 3GPP. It is important to understand that $5 \mathrm{G}$ network will be a densified network with more connected devices, high data rates anytime and anywhere, uninterrupted service to moving users and extremely low-latency to tactile internet. The ongoing research and limitations yet to be discovered are focused so that we can have a clear understanding as to how much really it will cost us to redesign today's infrastructure to 5G. The rest of the paper is arranged as follows, section II covers $5 \mathrm{G}$ envisions from industry and academia, section III 
covers 5G architecture, section IV covers 5G Trials and Implementation, section $\mathrm{V}$ covers Standardization activities of $5 \mathrm{G}$ and finally the paper ends with section VI, the conclusion.

\section{II $5 \mathrm{G}$ ENVISIONS}

\section{A. Towards Green and Soft: A 5G Perspective [5]}

In [9], authors emphasize on energy efficiency (EE) and spectral efficiency (SE) co-design, no more cells, rethinking signaling/control, invisible base stations, and full duplex radio as the essential ingredients of 5G. Authors argue that scarce spectrum, dramatic rise in demand capacity leads us to be spectral efficient, whereas the rise in energy consumption of Information and communications technologies (ICT) is becoming a matter of concern. Antenna re-engineering, redesigning base station and efficient use of radio, signaling and control are the some key areas which can meet the demand of $5 \mathrm{G}$.The criteria of $5 \mathrm{G}$ networks includes higher spectral efficiency (SE) and energy efficiency (EE), lower end-to end latency, and more connection nodes. According to China Mobile, 5G should reveal two major concepts: green and soft.Green refers to a greener environment to avoid increase in amount of $\mathrm{CO}_{2}$ and hence global warming [10] whereas soft means to reduce the total energy consumption [11]. EARTH[12], a research group claimed the use of lowloss antennas, micro direct transmission (DTX), antenna muting, and adaptive sectorization depending on traffic fluctuations, will cause an energy savings of 60-70 \%, whereas GreenTouch aims to improve energy efficiency (EE) 1000 times by 2020. [13].Antenna muting [EARTH], increasing the number of antennas are introduced to improve EE. An ideal EE-SE curve should have the following properties:1)For every SE operation point, the EE value should be better.2) The EESE area should be increased and trade-off area should be decreased.3) Slope in trade-off portion should be less than before.

The concept of cellular systems proposed by Douglas H. Ring and W. Rae Young cannot cope up with varying traffic and divergent condition. Thus for $5 \mathrm{G}$ networks the concept of no more cell is used with soft technologies [14]. It uses data decoupling scheme, where the macro cell is used for control and the small cell for data. When there is no data, small cell can be turned off to save energy. Here, C-RAN is another way to efficient energy.For a network structure without $\mathrm{BS}$, the paper focuses on health issues caused by BS and other difficulties that force to deploy 'conformal arrays' of antennas on front or exterior of a building or on water tanks in countryside. To study various challenges of massive MIMO or large scale antenna system (LSAS), Third Generation Partnership Project (3GPP) and other research groups such as WINNER are involved. Although several challenges are addressed, pilot contamination, massive MIMO propagation is not taken into account. The paper also does not encounter the applications of smarter devices. For rethinking signaling, it is seen that the exponential rise in data traffic causes battery drainage and overhead in mobile networks. The proposed solutions are: use of lightweight radio resource connection (RRC) state without maintenance and the second is a slim radio signaling interaction. Due to health issues, the deployment of BS can be replaced by irregular antennas acting as invisible BS.Finally a full duplex BS is employed not only because it has self-interference cancellation mechanism [15] but also it doubles SE and increments EE.

\section{B. Network densification}

In [16] according to Martin Cooper, founder of cellular communications, the expansion of wireless system capacity depends on three main features: 'wireless infrastructure nodes', 'radio spectrum', and 'link efficiency'. As per stated in an additive white Gaussian noise (AWGN) channel, the throughput of a user is upper-bounded by $\mathrm{R}<\mathrm{C}=\mathrm{m}(\mathrm{W} / \mathrm{n}) \log 2(1+\mathrm{s} / 1+\mathrm{N})$ where $\mathrm{W}$ refers to the base station signal bandwidth, $\mathrm{n}$ (load factor) is the number of users sharing the given base station, $\mathrm{m}$ (spatial multiplexing factor) is the number of spatial streams between a base station and user device(s), and $\mathrm{S}$ is the wanted signal power, $\mathrm{I}$ is interference and $\mathrm{N}$ is noise power, at the receiver. These can be related to the term "network densification." It is defined as the merging of spatial densification and spectral aggregation. Spatial densification is where a heterogeneous network consists of macrocell, picocell and relays. The installation of macrocell is expensive and unplanned which imposes the deployment of low-power nodes (small cell) of which outdoor cell are known as picocell. Places where 'wired backhaul access' cannot reach relay nodes are exploited. The variation in traffic demand restricts the application of small cell to be advantageous, to make effective use cell range expansion can be a process. It diminishes the issue of co-channel implication of low-power nodes by biasing handoff boundaries toward small cells. Advanced Interference Cancellation is another method that consists of linear and non-linear cancellation to eliminate dimension loss [16].Neighborhood small cell (NSC) solution provides a cost effective answer to spatial densification, and deals with 1000 times more data traffic in future networks. It uses self-organizing network (SON) method that consists of the following features: 1) Selfconfiguration: 2) Mobility management 3) Backhaul load balancing. Device-to-device communications has its advantageous in terms of enhance user experience, lowers power usage and latency, high data rates, etc [17], [18].

Spectral aggregation consists of spectrum availability and multiband operation. The RF Transceiver design challenges include: RF front-end (RFFE) planning faces several difficulties in terms of cost and power efficiency due to 
manifold of frequency band, MIMO and co-use of radio. To provide service around 40 wide area networks (WAN) any one of the following two methods can be applied: 1) abundant supply of fixed frequency filters or 2) use high $\mathrm{Q}$ tunable RF filters and then apply broadband RFFEs. [19] In millimeterwave technology, the cellular networks can take advantage of mmWave in $30-300 \mathrm{GHz}$ region [20,21]. Although it imposes variety of negative factors that need to be overcome, such as high path loss, absorption of signal by material in earth and many more. Several drawbacks are already fixed whereas others are yet left out. The backhaul densification ensures high data rate with increasing demand, we need BS connected to high- capacity, reduced latency backhaul links. There are two ways to resolve the problem, first, Cloud-RAN architecture, second is wireless backhaul technologies [22].

\section{5GNOW: Non-Orthogonal, Asynchronous Waveforms for Future Mobile Applications}

The main context is the deployment of non-orthogonal asynchronous waveform and a dramatic change in PHY layer to meet the requirements of $5 \mathrm{G}$ drivers. The major activators of $5 \mathrm{G}$ are: 1) Internet of Things (IoT): number of devices is likely to rise around 100,000 machine-type communication where 'scalability' will be a complication.2) Gigabit wireless connectivity: the data rates are assumed to be around $10 \mathrm{~Gb} / \mathrm{s}$ to provide wireless connectivity to a mass of people.3) Tactile Internet: the main intention is to achieve low latency on network with round trip time RTT around $1 \mathrm{~ms}$ for real-time programs. Thus to meet the challenges of high data rate, low latency, scalable networks, improved energy and spectrum of radio access, an implication of redesign of PHY layer.

The next step is to understand the reason for a changed waveform. Synchronism means that the senders work with a synchronized (common) clock for their processing. Orthogonality refers to the receivers' waveform detection process without any crosstalk. When the orthogonality gets cancelled, the distortion increases without any limit, some illustrations are given to support the statement. 1) sporadic traffic: the use of rough synchronization lessen overhead signal and operational activities gets better.2) spectral and temporal fragmentation: LTE-A seems to reduce spectral efficiency or prohibit the use of guard band claiming the need to leave orthogonal-synchronized waveform for a new one [23], [24] .3) real-time constraints: asynchronous waveforms are more convenient to obtain tactile internet with ultra-low latency with a transmission time interval (TTI) of $1 \mathrm{~ms}$.

The next section describes the modified architecture of PHY layer of 5G.1) unified uplink frame structure vision: to deal with various types of traffic it is essential to handle them efficiently. Type I is classical bit pipe traffic, vertical layering acts as a solution. Type II is multi-cell multi-user transceiver, interleave-division multiple access (IDMA) [25] is used here. Type III is sporadic traffic where a contention-based access method is used. Lastly, type IV is sensor-type traffic, here the open Weightless initiative (http://www.weightless.org/) is an answer.2) dealing with heterogeneous traffic types: Universal filtered multi-carrier (UFMC) [26], is an approach that takes in the benefits of filtered orthogonal frequency division multiplexing (OFDM) and filter bank multicarrier (FBMC) [24] and leave out the drawbacks. Various simulation results and graphs are plotted which shows UFMC performs better than others. 3) sparse signal processing:this is to determine and demodulate MTC traffic in PHY layer .4) comp robustness framework: this consists of Time and Frequency Synchronization [27] and Imperfect channel state information CSI [28], [29]. The users at the edge of cell usually face interference that affects cell throughput as they are far away from BS. The CoMP between adjacent cells provides two BS for edge users to overcome this issue [30]. 5) achieving very short latency: ultra-low latency is one of the essential factors for real-time applications and 'tactile internet'. To overcome this challenge, generalized frequency-division multiplexing (GFDM) [31, 32] is applied. The process of circular convolution generates several benefit including cyclic prefix and suffix, relaxing the requirement of time domain synchronization.

In conclusion, the paper gives appropriate evidence as to why we should leave orthogonal-synchronous wave and shift to asynchronous-non- orthogonal waveforms. For instance UFMC, FBMC, GFDM, are chosen over OFDM due to their influential characteristics.

\section{Cellular Architecture and KeyTechnologies for 5G WirelessCommunication Networks}

This paper illustrates cellular architecture and other key factors that determine 5G networks: massive MIMO, energy efficient communication, cognitive radio networks and visible light communication. It provides statistics and compares 5G with $4 \mathrm{G}$ networks to provide us a clear understanding as to why we are concerned and should move to $5 \mathrm{G}$ networks. Wireless World Research (WWR) predicts 7 trillion wireless devices will be used by 7 billion people. The steep rise in wireless devices and people craving for faster internet wherever they are imposes two momentous challenges on us. The first one is the inadequacy of radio frequency, cellular phone use frequencies from hundred $\mathrm{MHz}$ to $\mathrm{GHz}$ heavily that there is not much to use now. Second is the cost of establishing the wireless networks in terms of energy and electricity consumption.[33]

When indoor users communicate with outdoor users, the signals penetrates through building walls resulting penetration loss damaging data rate, spectral and energy efficiency. To avoid these, distributed antenna arrays and massive MIMO 
technologies [34] are used. Large antenna arrays will be installed in outdoor BS and outside every building which, despite of increasing cost it would be beneficial in the long run. mmWave and visible light communication (VLC) will be used to increase data rate transmission indoor. Here the context talks about mmWave only in terms of energy efficiency, high data rate and high quality service but does not discuss key features, algorithms used, blockage areas and hardware limitation. Another important challenge 5G accounts is user mobility (vehicle, high speed train), the use of macrocell, microcell, small cell and relays can work as a remedy.

One of the promising key discussed here is Massive MIMO, where multiple antennasis installed in both transmitter and receiver. This enhances the chance of gathering more information thus improving reliability, spectral and energy efficiency. It also diminishes the effect of noise and intracell interference. According to [34],MIMO helps to avoid complicated algorithm. The focus remains on the theoretical successes without any evidence of real case or discussing the limitations of MIMO(channel estimation, pilot contamination) ,MIMO propagation. Although later it provides latest progress in massive MIMO channel models. It proposes SM concept to massive MIMO systems for betterment of signal processing complexity so that the channel estimation does not need to be exact, differentiating each transmit antenna would be suffice.Spatial modulation is a technique to enhance the performance of MIMO. SM sends a part of data to the transmission antenna, this in turn increases the data rate (spatial multiplexing). Spatial multiplexing is used in massive MIMO. SM solves three major issues including interchannel interference, inter-antenna synchronization and multiple RF chains [36]. It is seen that the multiplexing gain increases logarithmically, thus multi-user SM is considered as a research topic in 5G (no limitation described).

The next one is cognitive radio networks; this is considered to be a method to utilize the congested RF spectrum. Here there are two scenarios: interference -free and interference tolerant basis. A slight change in user density, interference threshold and transmission behavior can alter performance of CR. CR increases spectral efficiency of the system. Mobilefemtocell is an important enabler for $5 \mathrm{G}$ networks that assists smooth mobility. These can be installed in public bus, high-speed train and cars to ensure quality service to users. It uses mobile cell relay with femtocell (mfemtocell) which improves spectral efficiency and can reduce overhead signal.VLC uses white light emitting diodes (LEDs), illuminates such products as well as transmit broadband wireless data connectivity from them. Optical attocells are introduced based on VLC that act as indoor small-cell cellular network. From a study it can be established that users with attocell can share 100 times more bandwidth than users with femtocellA keen look to our environment would suggest us to design future networks such that it can reduce $\mathrm{CO}_{2}$ and be a step ahead to be greener. Indoor networks are an appealing strategy to be energy efficient. Separating indoor and outdoor networks, where macro BS can transmit with low power is also another way to be efficient. The practice of VLC and mmWave is also another approach to green communication.

The paper takes the turn of the context in elaborating challenges in 5G networks.1)To begin with, the parameters should be decided upon which the $5 \mathrm{G}$ characterizations will be measured such as spectral efficiency, energy efficiency, delay, reliability, fairness of users, QoS, implementation complexity, and many more. 2) To understand that massive MIMO needs change the whole architecture compared to the conventional MIMO and how to define non-stationary high-mobility channels is a matter of concern[14]. 3)To reduce signal processing proximity in massive MIMO, SM concept is included which will not need the channel estimation to be identical but rather be enough to differentiate each transmit antenna.4)To reduce interference, temperature model, a feedback mechanism in interference-tolerant CR networks can be used. CR transmitters can coordinate with each other to decide the transmit power and prevent the interference

\section{E. What will 5G be}

The paper provides an encyclopedic approach to $5 \mathrm{G}$ networks elaborating the requirements, challenges and research works. The annual visual network index (VNI) reports of Cisco affirms that enormous rise in data will occur in future along with the upsurge in connected device and data rates. Academic communities are involved in projects such as METIS [2] and 5GNOW [3] and industries are delivering preparatory details of $5 \mathrm{G}$. To begin with, the factors that should be included in $5 \mathrm{G}$ are 1) data rate, 2) latency and 3) energy and cost. Among these the foremost attractive factor remains "high data rates" and is described in account of three major features: network densification, mmWave, and massive MIMO.

A: Extreme Densification and Offloading: An easy solution is to reduce size of cells make the cells smaller [37], [38] to reuse frequency and reduce competition among users. The critical areas of this method are: 1) Base Station Densification Gains provides detailed works and examples that were not present in [1] 2) Multi-RAT Association talks about mmWave in terms of blockage with real life example from special issues [39],[40]-[41],[42] 3) Mobility Support described in [43], [44]. 4) Cost .It is seen that several challenges are described .B. Millimeter Wave:mmWave is explained in terms of 1)propagation loss (path loss, blocking [45, ][46][53],Atmospheric and rain absorption [54], [55]), 2)Large arrays, narrow beams (Link acquisition, Leveraging the legacy 4G network [56], [57], Novel transceiver architectures needed [58]-[61].Extensive details of mmWave characteristics in terms of limitation (path loss, blockage, atmospheric conditions) and current works in explaining them[49- 


\section{International Journal of Engineering Applied Sciences and Technology, 2019 \\ Vol. 4, Issue 3, ISSN No. 2455-2143, Pages 20-34 \\ Published Online July 2019 in IJEAST (http://www.ijeast.com)}

55],[[56], [57],[46]. The simultaneous use of mmWave for data and macrowave for control plane, power consumption of D/A, A/D, already mentioned in [1], provides more information [59] and [60], [61].C. Massive MIMO- The use of MU-MIMO, CoMP relays on massive MIMO and their benefits are explained [62-64]. The limitations include : 1) Pilot Contamination and Overhead Reduction 2) Architectural Challenges:[65] 3) Full-Dimension MIMO and Elevation Beam forming, it provides cell average and edge data rates from Samsung's network simulator 4) Channel Models: A recent study on 3D channel modeling is described in [66] and [67],[68] 5) Coexistence with Small Cells: Co-use of massive MIMO with small cells, such ideas will be ascertained by cost and backhaul. 6) Coexistence with mmWave: The use of massive MIMO applications at mmWave frequencies would have to determine well-balance between power gain/interference reduction and parallelization

The design issues consist of the following:1)The Waveform: Signaling and Multiple Access: Several approaches OFDM and OFDMA are used along with their drawbacks [69-71]. Second views to eliminate the disadvantages are described in [72-75] Potential Alternatives to OFDM. 2) Cloud-based Networking: 1) Network Function Virtualization: NFV [7678] allows network functions to shift towards cloud computing from hardware appliances. 2) Software Defined Networking:[79]. 3) energy efficiency is explained in terms of Resource allocation, network planning, renewable energy: and hardware solutions. Standardization for $5 \mathrm{~g}$ consists of: 1) Spectrum Policy and Allocation includes Exclusive Licenses [80], [81],Unlicensed Spectrum [82], Spectrum Sharing [83], [84] and Market-Based Approaches to Spectrum Allocation [85]- [88] 2) Regulation and Standardization includes 5G Standardization Status, 5G Spectrum Standardization 3) Economic Considerations includes Infrastructure Sharing and Backhaul.

This work can be seen as an answer to our visionary paper [Five disruptive], it provides solution to several questions and resolve issues using various techniques. It is enriched with huge amount of information that enhances our knowledge on $5 \mathrm{G}$ network structure.

\section{F. NOKIA- looking ahead to 5G}

Nokia envisions "5G will enable a scalable service experience anytime and everywhere and where people and machines obtain virtual zero latency and gigabit experience where it matters" .Nokia, hopes the communication of $5 \mathrm{G}$ beyond 2020, will be a fusion of existing and ongoing projects (LTE$\mathrm{A}, \mathrm{Wi}-\mathrm{Fi}$ ) combined with new For instance: in future we desire high data rate with reduced latency. Low-latency is especially important in terms of mobility
The context focuses initially on three key advancement in 5G which includes more spectrum introduced, densified network with small cell and increased performance of the network altogether.1)Bridging the spectrum gap with 5: It is predicted that to meet the rising demand beyond 2020, spectrum above $10 \mathrm{gHz}$ will be required. Different patterns are accustomed to systems with low and high frequency bands. Affordability is also crucial, so the harmonization of radio frequency bands will be important to enable economies of scale and roaming.This will also minimize interference across borders.2) Optimizing the use of spectrum: The main concern is to search for new spectrum as well as productively make use of the existing one. Authorized Shared Access (ASA), also known as Licensed Shared Access (LSA) is a regulatory theory that permits sharing spectrum under suitable condition. CoPrimary Shared Access models and cognitive radio access theories provide high peak data rates with higher capacity and coverage. 3) Adapting radio access technology to frequency band in use: two sides of the coin. Nokia introduces new frame design with a flexible UL/DL pattern that will support more flexible adaptation itself in various scenarios another way is the use of millimeter wave bands will give access to available spectrum but they will have different propagation properties..)4) Networks to become denser with small cells: As predicted, the number of connected device will be 10-100 times more than today both with small cell and base stations with various transmit power and coverage area. The introduction of ,the utilization of traditional frequencies, new frequency in mmWave, small-cell-optimized RAT, are used to meet the throughput and latency demand with the focus to take access points closer to users, reducing RTT and increase efficiency. mmWave is also used in access and backhaul. Nokia launched Brooklyn summit in spring 2014, to share and debate about propagation measurements, techniques, design complications. For device-to-device, machine-type and selfhauling remodeled OFDMA numerology, MAC and novel higher layer concepts are suggested. New frame designs with redesigned uplink/downlink are recommended. 5) Network performance: Nokia measures out the performance metrics in the following order: Round Trip Time (RTT), Spectral efficiency, Self-backhauling and direct device-to-device Low power consumption, Ultra-low cost per access node, Higher layer protocols and architecture

RTT is one of the crucial performance measures in $5 \mathrm{G}$, here the main concern in to achieve extremely low latency. The goal is to have less than $1 \mathrm{~ms}$ RTT with virtual zero delay experience. Self-backhauling and direct device-to-device this becomes a significant factor to develop better balance between expense and performance of extreme- dense networks. Research Activities include projects with METIS, ITUR,China IMT-2020 and 3GPP. The main aim is to achieve supple use of spectrum, system design in extremely dense small cell structure, high data rates with lowest latency, works on mmWave and so on. 
To conclude, this section tries to provide an extensive summary of $5 \mathrm{~g}$ by selecting major papers contributing in this technology. This is done so that light is shed on all areas of this technology so that a clear understanding can be captured.

Table -1 Comparison of major five $5 \mathrm{G}$ requirements

\begin{tabular}{|c|c|c|c|c|c|c|c|}
\hline Type & $\begin{array}{c}\text { Five } \\
\text { Disruptive } \\
\text { Technology } \\
\text { Directions } \\
\text { for 5G }\end{array}$ & $\begin{array}{c}\text { Toward } \\
\text { Green and } \\
\text { Soft: A 5G } \\
\text { Perspective }\end{array}$ & $\begin{array}{c}\text { Network } \\
\text { Densification }\end{array}$ & $\begin{array}{l}\text { 5gnow:Non- } \\
\text { Orthogonal, } \\
\text { Asynchronous } \\
\text { Waveforms } \\
\text { for Future } \\
\text { Mobile } \\
\text { Applications }\end{array}$ & $\begin{array}{c}\text { Cellular } \\
\text { Architecture } \\
\text { and Key } \\
\text { Technologies for } \\
\text { 5G Wireless } \\
\text { Communication } \\
\text { Networks }\end{array}$ & $\begin{array}{l}\text { What Will } \\
\text { 5G Be? }\end{array}$ & $\begin{array}{c}\text { nokia:looking } \\
\text { ahead to 5G }\end{array}$ \\
\hline $\begin{array}{l}\text { device- } \\
\text { centric }\end{array}$ & figure & $\begin{array}{l}\text { USER- } \\
\text { CENTRIC } \\
\text { DESIGN }\end{array}$ & $\begin{array}{l}\text { Illustration } \\
\text { with SINR }\end{array}$ & $\begin{array}{l}\text { CoMP-graph } \\
\& \text { calculation }\end{array}$ & $\begin{array}{l}\text { CR networks for } \\
\text { spectrum(4) }\end{array}$ & $\begin{array}{c}\text { Base Station } \\
\text { Densification } \\
\text { Gains: } \\
\text { calculation }\end{array}$ & $\begin{array}{l}\text { Details of } \\
\text { Spectrum }\end{array}$ \\
\hline mmWave & $\begin{array}{l}\text { Graph- } \\
\text { comparison } \\
\text { with math }\end{array}$ & no & Illustration & No & No description & Calculation & describe \\
\hline $\begin{array}{l}\text { Massive } \\
\text { MIMO }\end{array}$ & $\begin{array}{c}\text { Graph- } \\
\text { comparison } \\
\text { with math }\end{array}$ & $\begin{array}{l}\text { Or LSAS } \\
\text { simulation }\end{array}$ & Description & No & describe/graph & $\begin{array}{c}\text { Data \& } \\
\text { calculation }\end{array}$ & no \\
\hline $\begin{array}{c}\text { Smarter } \\
\text { device }\end{array}$ & $\begin{array}{l}\text { Graph with } \\
\text { math }\end{array}$ & no & D2D:graph & No & No description & $\begin{array}{l}\text { through out } \\
\text { the paper }\end{array}$ & description \\
\hline M2M & graph & no & $\begin{array}{l}\text { backhaul } \\
\text { densification } \\
\text {-to reduce } \\
\text { latency }\end{array}$ & $\begin{array}{l}\text { Latency- } \\
\text { simulation } \\
\text { /real time }\end{array}$ & $\begin{array}{l}\text { Address the issue } \\
\text { of explosion of } \\
\text { connection } \\
\text { device in } \\
\text { number,reliability }\end{array}$ & $\begin{array}{l}\text { design } \\
\text { choices }\end{array}$ & $\begin{array}{c}\text { latency- } \\
\text { describe,reality }\end{array}$ \\
\hline
\end{tabular}

III. AN ARCHITECTURAL OVERVIEW ON 5G

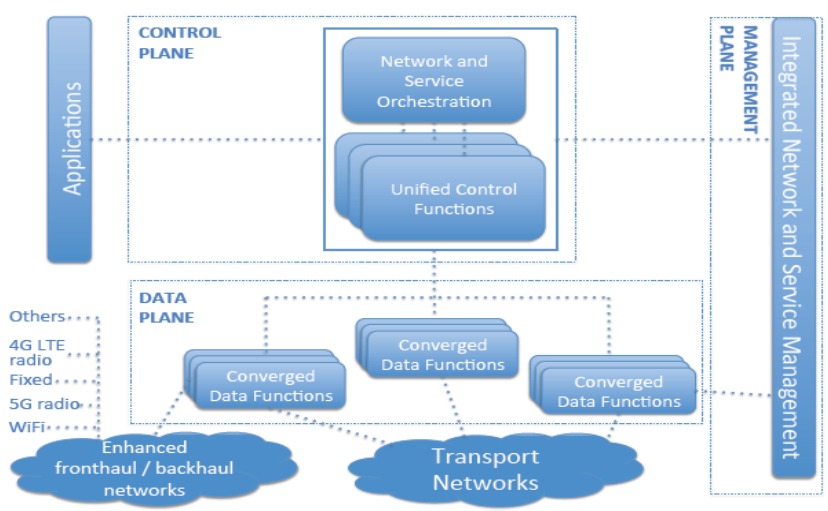

Fig.1. High-level view of 5G network architecture [89]
The figure shows high level architecture of 5G [90] which is constructed depending on the criteria of 5G. Along with several use cases, the Network Operation (NEO) deals with system exibility, scalability, mobility support, efficient content delivery, self-backhauling and interworking with 4G. Here, the main purpose is to successfully satisfy the diversified demands of $5 \mathrm{G}$ network. The backbone of physical infrastructure is based on software-defined networking (SDN) and Network Functions Virtualization (NFV). The next important issue is to define network slicing. 


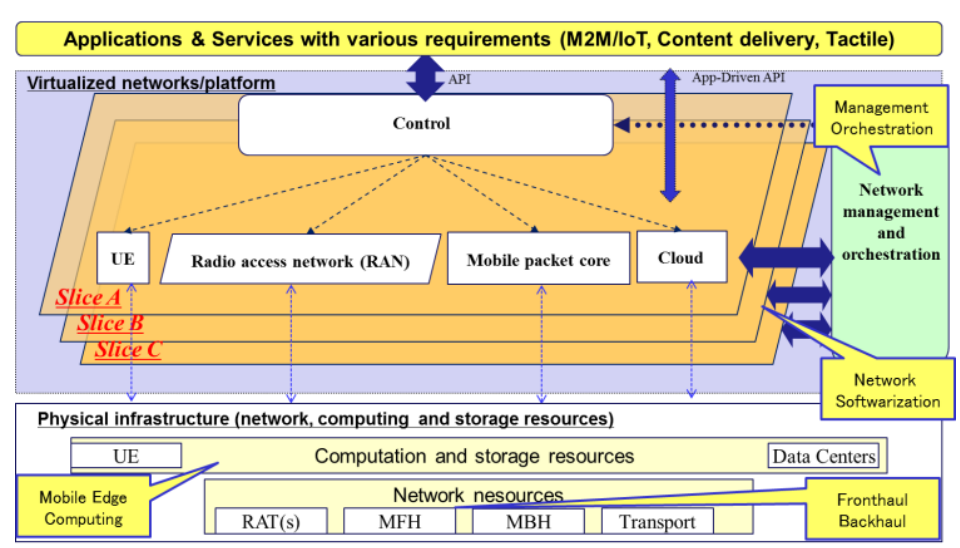

Fig. 2. Network softwarization view of 5G networks [91]

The "slicing concept" is the main component of Network Softwarizatrion which was first declared in Academia, NetSoft 2015.It includes Software Defined Networking (SDN) and Network Functions Virtualisation (NFV) , Network Virtualization, Mobile Edge Computing, Cloud and IoT technologies. The slicing methodology can be described as a logically isolated network partitions (LINP) [ITU-T Y.3011], [ITU-T Y.3012]. Slice is defined as a unit of programmable resources which might consist of network, computation and storage. Due to vast diversified application domainsof 5G or IMT-2020 network, it is required to enhance the slicing method so that it can support more number of use cases than the existing SDN/NFV technologies.

Horizontal extension to slice includes enhanced end-to-end communication in terms of quality. The $5 \mathrm{G}$ network slices should be developed so that it can enhance the quality and services of end-to-end communication that is, from user equipment (UE) to cloud. Since there will be rapid growth in the wireless part of the network, the permanent section of the network should take over the end part of the communication. In vertical extension to slice it is important for $5 \mathrm{G}$ networks to take into consideration the data-plane programmability and programmable interface. Along with SDN, the vertical extension of $5 \mathrm{G}$ should also work with these. Because of the use of NS, the system should grasp the following requirements to make sure it can be scaled if need :how many service slices should be there, what should the service slice deliver, how many service sessions can be used simultaneously, intra-slice and inter-slice coordination.

The programmable interface and resource abstraction should also meet certain requirements and criteria so as to provide flexibility and agility. In federation and isolation], the necessities may differ based on 5G services and applications. The key is to able to differentiate resources per slice. Every slice will be logically isolated and the resource usage in a slice should not be affected by that in other slices. The vertical interaction and horizontal federation among multiple slices to produce new and end-to-end services are also needed. In terms of Application driven direct programmability [91], it is evident that not all the components of $5 \mathrm{G}$ mobile networks can be described as software, some may be programmable. This decision is taken by considering the balance between the performance and programmability.

To conclude, the Figure describes the architectural steps of $5 \mathrm{~g}$ which consists of NFV and SDN.

\section{5G TRIAL AND IMPLEMENTATION}

The figure shows a timeline of real life experiments, test cases and execution of 5G networks from the year 2016 to 2018. It is seen that $5 \mathrm{G}$ was first experimented in 2016 in Oulu Finland. Since 2016 was only a starting year of experimentation, there are not many activities in it. However, the following year shows a steep number of research outcomes of MIMO, distributed antenna, end-toend $5 \mathrm{G}$ trials and many more. Many renowned companies including Samsung, Cisco, Nokia, Huawei competes with their ideas. On the other hand in 2018, there are three implementations carried out in just one month deploying us the idea that $5 \mathrm{G}$ can actually be achieved within the year 2020 .

This section tries to provide details about the trials and sheds light on where $5 \mathrm{G}$ is already used in real life scenario. The table shows list of areas and the company sponsoring the $5 \mathrm{G}$ network in the timeline of 2 years. 


\section{International Journal of Engineering Applied Sciences and Technology, 2019 Vol. 4, Issue 3, ISSN No. 2455-2143, Pages 20-34 \\ Published Online July 2019 in IJEAST (http://www.ijeast.com)}

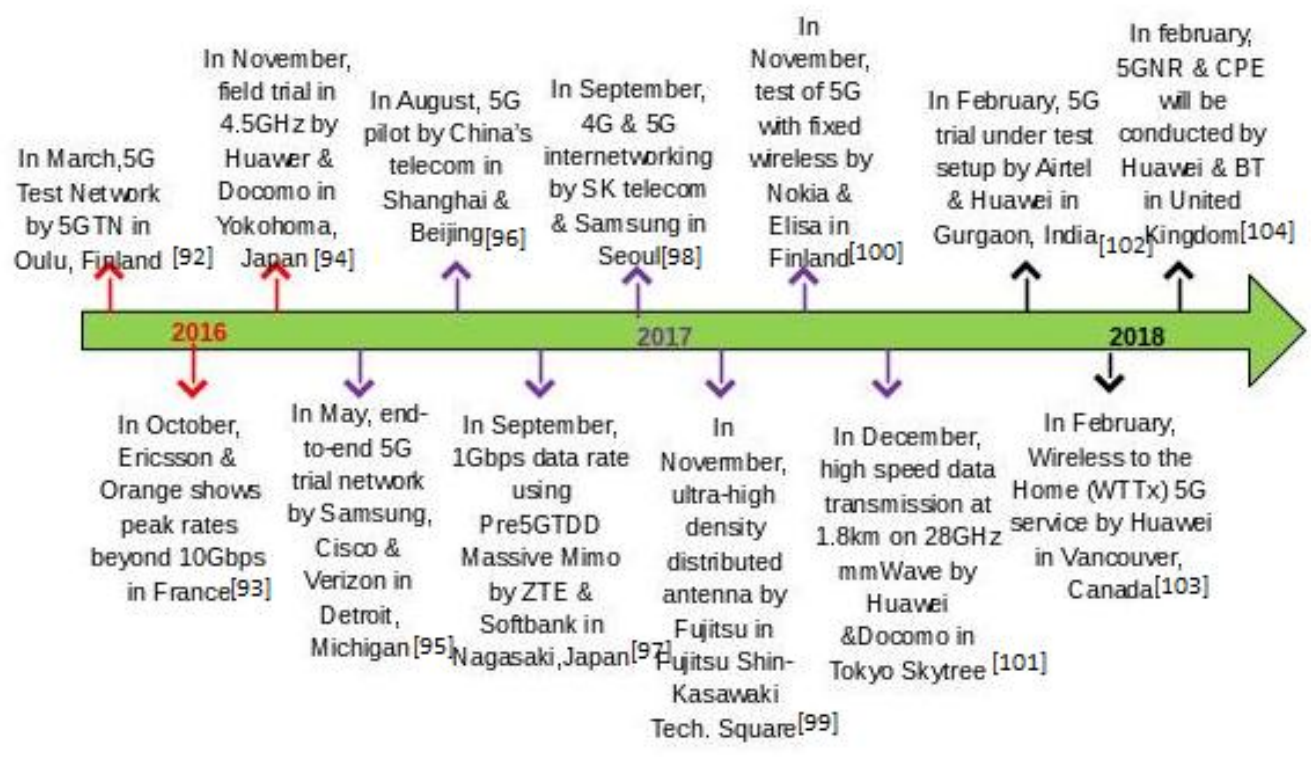

Fig.3. Trial and implementation of 5G from 2016 to 2018

\section{STANDARDIZATION ACTIVITIES OF 5G}

The Internet Engineering Task Force (IETF) is an organization with a group of people with contribution to different sections of Internet, i.e: engineering and evolution. It is responsible for development of certain Internet standards thus any new criteria coming into the telecommunication sector should be discussed and permitted by IETF. Engineers from different institution contribute to IETF regarding 5G activities from 2015 till now are shown in the Fig.

ITU (International Telecommunication Union)

Due to a steep demand in ICT sector[106], with aheterogeneous 5G network to be implemented within 2020, the ITU (International Telecommunication Union) and IMT (International Mobile Telecommunication) system are working to make this vision realistic. In 2012 when ITU-R (ITU Radiocommunication Sector) initiated a program to research on 5G named "IMT for 2020 and beyond"

The following table shows the current ITU-T (ITU Telecommunication Standardization Sector (ITU-T)) standards regarding IMT 2020 divided into different categories. Professionals around the world submit their work to encourage international standards acknowledged as ITU-T Recommendation. 
International Journal of Engineering Applied Sciences and Technology, 2019

Vol. 4, Issue 3, ISSN No. 2455-2143, Pages 20-34

Published Online July 2019 in IJEAST (http://www.ijeast.com)

Table- 2 List of IETF documents on 5G[105]

\begin{tabular}{|c|c|c|c|c|c|}
\hline SL & Proposed by & Institution & Validity & versions & name \\
\hline \multirow[t]{3}{*}{1} & \multirow[t]{3}{*}{ I.Johansson } & \multirow[t]{3}{*}{ Ericsson $\mathrm{AB}$} & $\begin{array}{l}\text { Oct. } 14,2015- \\
\text { Apr. } 16,2016\end{array}$ & 00 & $\frac{\text { Congestion control for } 4 \mathrm{G} \text { and } 5 \mathrm{G} \text { access }}{\text { v. } 00}$ \\
\hline & & & $\begin{array}{c}\text { Apr .12, 2016- } \\
\text { Oct.14, } 2016\end{array}$ & 01 & $\begin{array}{c}\frac{\text { Congestion control for 4G and 5G access }}{\text { v.01 }} \\
\end{array}$ \\
\hline & & & $\begin{array}{l}\text { Jul. 20, 2016- } \\
\text { Jan. } 21,2017\end{array}$ & 02 & $\frac{\text { Congestion control for } 4 \mathrm{G} \text { and } 5 \mathrm{G} \text { access }}{\text { v. } 02}$ \\
\hline 2 & $\begin{array}{l}\text { C.Chen } \\
\text { X.Wei }\end{array}$ & $\begin{array}{l}\text { Huawei } \\
\text { Technologies Co., } \\
\text { Ltd }\end{array}$ & $\begin{array}{l}\text { Oct. 31, 2016- } \\
\text { May 4, } 2017\end{array}$ & 00 & $\frac{\text { ID locator Split Based Solution for 5G }}{\text { networks v.00 }}$ \\
\hline \multirow[t]{2}{*}{3} & \multirow[t]{2}{*}{$\begin{array}{l}\text { D. von Hugo. } \\
\text { B. Sarikaya }\end{array}$} & \multirow[t]{2}{*}{$\begin{array}{l}\text { Telekom Innovation } \\
\text { Laboratories. } \\
\text { Huawei }\end{array}$} & $\begin{array}{l}\text { Sep. } 14 \text { 2016- } \\
\text { Mar. } 18,2016\end{array}$ & 00 & $\begin{array}{l}\frac{\text { Review on issues in discussion of next }}{\text { generation converged networks }(5 \mathrm{G}) \text { from }} \\
\text { an IP point of view v.00 }\end{array}$ \\
\hline & & & $\begin{array}{l}\text { Nov. 13, } \\
\text { 2016- May 17, } \\
2017\end{array}$ & 01 & $\begin{array}{l}\frac{\text { Review on issues in discussion of next }}{\text { generation converged networks }(5 \mathrm{G}) \text { from }} \\
\underline{\text { an IP point of view v. } 01}\end{array}$ \\
\hline \multirow[t]{2}{*}{4} & \multirow{2}{*}{$\begin{array}{l}\text { R.Moskowitz } \\
\text { X.Xu } \\
\text { B.Liu }\end{array}$} & \multirow[t]{2}{*}{ Huawei } & \begin{tabular}{|l|} 
Sep. 27, 2016- \\
Mar. 31, 2017 \\
\end{tabular} & 00 & $\begin{array}{l}\frac{\text { HIP Enabled ID/Loc separation for fast }}{\text { 5GPP IP mobility v.00 }} \\
\end{array}$ \\
\hline & & & $\begin{array}{l}\text { Oct. 27, 2016- } \\
\text { Apr. 30, 2017 } \\
\end{array}$ & 01 & $\frac{\text { HIP Enabled ID/Loc separation for fast }}{\underline{\text { 5GPP IP mobility v.01 }}}$ \\
\hline \multirow[t]{2}{*}{5} & \multirow[t]{2}{*}{$\begin{array}{l}\text { D. von Hugo. } \\
\text { B. Sarikaya }\end{array}$} & \multirow[t]{2}{*}{$\begin{array}{l}\text { Telekom Innovation } \\
\text { Laboratories. } \\
\text { Huawei }\end{array}$} & $\begin{array}{l}\text { Feb. 23, 2017- } \\
\text { Aug. 27, } 2016\end{array}$ & 02 & $\begin{array}{c}\frac{\text { Review on issues in discussion of next }}{\text { generation converged networks }(5 \mathrm{G}) \text { from }} \\
\text { an IP point of view v. } 02\end{array}$ \\
\hline & & & $\begin{array}{l}\text { Mar. 13, 2016- } \\
\text { Sep 14, } 2017\end{array}$ & 03 & $\frac{\begin{array}{l}\text { Review on issues in discussion of next } \\
\text { generation converged networks }(5 \mathrm{G}) \text { from }\end{array}}{\text { an IP point of view v.03 }}$ \\
\hline \multirow[t]{2}{*}{6} & \multirow{2}{*}{$\begin{array}{l}\text { D. von Hugo } \\
\text { Sarikaya } \\
\text { T.Herbert } \\
\text { K. Satish } \\
\text { R. Schott } \\
\text { S. Seo }\end{array}$} & \multirow{2}{*}{$\begin{array}{c}\text { Deutsche Telekom } \\
\text { Huawei } \\
\text { Quantonium } \\
\text { Nokia } \\
\text { Deutsche Telekom } \\
\text { Korea Telekom }\end{array}$} & $\begin{array}{l}\text { May 2, 2017- } \\
\text { Nov. 3, } 2017\end{array}$ & 00 & $\frac{\text { 5G IP Access and Session Management }}{\underline{\text { Protocols v.00 }}}$ \\
\hline & & & $\begin{array}{l}\text { May 22, 2017- } \\
\text { Nov. 23, } 2017\end{array}$ & 01 & $\frac{\text { 5G IP Access and Session Management }}{\underline{\text { Protocols v.01 }}}$ \\
\hline 7 & $\begin{array}{l}\text { R.Moskowitz } \\
\text { X.Xu } \\
\text { B.Liu }\end{array}$ & Huawei & $\begin{array}{l}\text { Jun. 26, 2017- } \\
\text { Dec. 28, } 2017\end{array}$ & 02 & $\frac{\text { HIP Enabled ID/Loc separation for fast }}{\text { 5GPP IP mobility v.02 }}$ \\
\hline 8 & $\begin{array}{l}\text { R. Ravindran } \\
\text { P. Suthar } \\
\text { G. Wang }\end{array}$ & $\begin{array}{l}\text { Huawei } \\
\text { Cisco } \\
\text { Huawei }\end{array}$ & $\begin{array}{l}\text { Oct. 29, 2017- } \\
\text { May 2, } 2018\end{array}$ & 00 & $\frac{\text { Enabling ICN in 3GPP's 5G NextGen }}{\text { Core Architecture v.00 }}$ \\
\hline 9 & $\begin{array}{l}\text { C.Chen } \\
\text { A.Pan }\end{array}$ & $\begin{array}{l}\text { Ericsson } \\
\text { Ericsson }\end{array}$ & \begin{tabular}{|l|} 
Dec. 28, 2017- \\
Jun.2018
\end{tabular} & 00 & $\frac{\text { Yang Data Model for Cloud Native } 5 \mathrm{G}}{\text { Core structure v.00 }}$ \\
\hline 10 & $\begin{array}{l}\text { D. von Hugo. } \\
\text { B. Sarikaya }\end{array}$ & $\begin{array}{l}\text { Deutsche Telekom } \\
\text { AG }\end{array}$ & $\begin{array}{l}\text { Jan. 28, 2018- } \\
\text { Aug.1, } 2018 \\
\end{array}$ & 00 & $\begin{array}{l}\text { IP Issues and Associated Gaps in Fifth } \\
\text { Generation Wireless Networks v.00 }\end{array}$ \\
\hline 11 & $\begin{array}{l}\text { R. Ravindran } \\
\text { P. Suthar } \\
\text { G. Wang }\end{array}$ & $\begin{array}{l}\text { Huawei } \\
\text { Cisco } \\
\text { Huawei }\end{array}$ & $\begin{array}{l}\text { Feb. 27, 2018- } \\
\text { Aug. 31, } 2018\end{array}$ & 01 & $\frac{\text { Enabling ICN in 3GPP's 5G NextGen }}{\text { Core Architecture v.01 }}$ \\
\hline 12 & $\begin{array}{l}\text { X. de Foy } \\
\text { M. Perras } \\
\text { U. Chunduri } \\
\text { K. Nguyen } \\
\text { M. Kibria } \\
\text { K. Ishizu } \\
\text { F. Kojima }\end{array}$ & $\begin{array}{c}\text { InterDigital } \\
\text { Communications } \\
\text { Huawei USA } \\
\text { NICT }\end{array}$ & $\begin{array}{l}\text { Mar.2, 2018- } \\
\text { Sep. 3, 2018 }\end{array}$ & 00 & $\frac{\text { Considerations for MPTCP operation in }}{\underline{5 \mathrm{G} v .00}}$ \\
\hline
\end{tabular}


International Journal of Engineering Applied Sciences and Technology, 2019

Vol. 4, Issue 3, ISSN No. 2455-2143, Pages 20-34

Published Online July 2019 in IJEAST (http://www.ijeast.com)

Table -3 A list of current ITU standards affiliated to IMT 2020[107]

\begin{tabular}{|c|c|}
\hline Categories & Approved Recommendation \\
\hline Service & $\begin{array}{l}\text { Y.3011: Framework of network virtualization for future networks } \\
\text { Y.3012: Requirements of network virtualization for future networks } \\
\text { Y.3300: Framework of software-defined networking } \\
\text { Y.3320: Requirements for applying formal methods to software-defined } \\
\text { networking } \\
\text { Y.3321: Requirements and capability framework for NICE implementation } \\
\text { making use of software-defined networking technologies }\end{array}$ \\
\hline Data & $\begin{array}{l}\text { Y.3031: Identification framework for future networks } \\
\text { Y.3032: Configuration of node IDs and their mapping with locators in future } \\
\text { networks } \\
\text { Y.3033: Framework of data aware networking } \\
\text { Y.3034: Architecture for interworking of heterogeneous component networks in } \\
\text { FNs }\end{array}$ \\
\hline Environment & $\begin{array}{c}\text { Y.3021: Framework of energy saving for future networks } \\
\text { Y.3022: Measuring energy in networks }\end{array}$ \\
\hline $\begin{array}{l}\text { Socio- } \\
\text { economic }\end{array}$ & $\begin{array}{l}\text { Y.3013: Socio-economic assessment of future networks by tussle analysis } \\
\text { Y.3035: Service universalization in future networks }\end{array}$ \\
\hline $\begin{array}{c}\text { Smart } \\
\text { Ubiquitous } \\
\text { Network }\end{array}$ & Y.3041, Y.3042,Y.3043,Y.3044,Y.3045 \\
\hline $\begin{array}{l}\text { Control } \\
\text { plane }\end{array}$ & $\begin{array}{l}\text { Q.3051:Signallingarchitecture for the control plane of distributed service } \\
\text { networking } \\
\text { Supplement } 67 \text { "Framework of signallingfor software-defined networking“ } \\
\text { Q.3315: Signallingrequirements for flexible network service combination on } \\
\text { broadband network gateway } \\
\text { Q.3711: Signallingrequirements for software-defined broadband access network } \\
\text { Q.3712: Scenarios and signallingrequirements of unified intelligent } \\
\text { programmable interface for IPv6 } \\
\text { Q.3713: Signallingrequirements for Broadband Network Gateway (BNG) pool } \\
\text { (under AAP, LC is } 28.03 .2017 \text { ) } \\
\text { Q.4040: The framework and overview of cloud computing interoperability testing }\end{array}$ \\
\hline
\end{tabular}




\section{International Journal of Engineering Applied Sciences and Technology, 2019 \\ Vol. 4, Issue 3, ISSN No. 2455-2143, Pages 20-34 \\ Published Online July 2019 in IJEAST (http://www.ijeast.com)}

\section{CONCLUSION}

To conclude, this survey tries to shed light in all sectors dealing with 5G. Considering "Five Disruptive Technology Directions for 5G" to be the visionary paper, we try to compare some other important paper in terms of their finding and discussion. 5G architecture is illustrated with slicing concept. The trial and implementations of 5G technology worldwide is listed which gives us a clear understanding of how far $5 \mathrm{~g}$ is. The paper ends with $5 \mathrm{G}$ activities by IETF and ITU. To the best of our knowledge, we tried to provide a complete scenario of $5 \mathrm{G}$ and its applications. It is the next big step with better speed, more users and devices to be connected at the same time, mobility of devices, etc. in one word, efficient and effective technology for mankind.

Acknowledgement: None. No funding

\section{REFERENCES}

[1] Boccardi, F., Heath Jr, R. W., Lozano, A., Marzetta, T. L., \& Popovski, P. (2013). Five disruptive technology directions for 5G. arXiv preprint arXiv:1312.0229.

[2] "FP7 European Project 317669 METIS (Mobile and wireless communications Enablers for the Twenty-twenty Information Society)," https://www.metis2020.com/, 2012

[3] "FP7 European Project 318555 5G NOW (5th Generation Non-Orthogonal Waveforms for asynchronous http://www.5gnow.eu/, 2012. signalling),"

[4] Wang, C. X., Haider, F., Gao, X., You, X. H., Yang, Y., Yuan, D., ... \& Hepsaydir, E. (2014). Cellular architecture and key technologies for $5 \mathrm{G}$ wireless communication networks. IEEE communications magazine, 52(2), 122-130..

[5] Chih-Lin, I., Rowell, C., Han, S., Xu, Z., Li, G., \& Pan, Z. (2014). Toward green and soft: A 5G perspective. IEEE

Communications Magazine, 52(2), 66-73.Naga Bhushan, Junyi Li, DurgaMalladi, Rob Gilmore, Dean Brenner, AleksandarDamnjanovic, Ravi TejaSukhavasi, Chirag Patel, and Stefan Geirhofer, "Network densification: the dominant theme for wireless evolution into 5G" IEEE Commun. Mag., vol. 52, pp. 82 - 89,Feb. 2014

[6] Andrews, J. G., Buzzi, S., Choi, W., Hanly, S. V., Lozano, A., Soong, A. C., \& Zhang, J. C. (2014). What will 5G be?. IEEE Journal on selected areas in communications, 32(6), 10651082.

[7] "Looking ahead to 5G - building a virtual zero latency gigabit experience," White Paper, Nokia Solutions and Networks, Dec. 2013. [Online]. Available:

http://nsn.com/sites/default/files/document/nsn 5g white paper.pdf

[8] http://www.smart2020.org.

[9] http://www.gesi.org.

[10] T. C. Group, "Smart 2020: Enabling the Low Carbon Economy in the Information Age," 2008.

[11] Skillermark, P., \& Frenger, P. (2012, May). Enhancing energy efficiency in LTE with antenna muting. In 2012 IEEE 75th Vehicular Technology Conference (VTC Spring) (pp. 1-5). IEEE.

[12] http://www.greentouch.org.

[13] C. M. R. Institute, "C-RAN: The Road Towards Green RAN," Oct. 2011, available: labs.chinamobile.com/cran

[14]E. Aryafaret al., "Midu: Enabling MIMO Full Duplex," Proc. ACM Mobicom '12, 2012.

[15] Damnjanovic, A., Montojo, J., Wei, Y., Ji, T., Luo, T., Vajapeyam, M., ... \& Malladi, D. (2011). A survey on 3GPP heterogeneous networks. IEEE Wireless communications, 18(3), 10-21.

[16] Wu, X., Tavildar, S., Shakkottai, S., Richardson, T., Li, J., Laroia, R., \& Jovicic, A. (2013). FlashLinQ: A synchronous distributed scheduler for peer-to-peer ad hoc networks. IEEE/ACM Transactions on Networking (ToN), 21(4), 12151228.

[17] Sadiq, B., Tavildar, S., \& Li, J. (2015). Inband device-to-device relays in cellular networks. arXiv preprint arXiv:1510.02519..

[18]Liu, X., Katehi, L. P., Chappell, W. J., \& Peroulis, D. (2010). High- Q Tunable Microwave Cavity Resonators and Filters Using SOI-Based RF MEMS Tuners. Journal of Microelectromechanical Systems, 19(4), 774784.

[19]Pi, Z., \& Khan, F. (2011). An introduction to millimeter-wave mobile broadband systems. IEEE communications magazine, 49(6), 101-107.

[20] Rappaport, T. S., Sun, S., Mayzus, R., Zhao, H., Azar, Y., Wang, K., ... \& Gutierrez, F. (2013). Millimeter wave mobile communications for $5 \mathrm{G}$ cellular: It will work!. IEEE access, 1, 335-349.

[21]E. G. Larsson et al., "Massive MIMO for Next Generation Wireless Systems," to appear, IEEE Commun. Mag.. 


\section{International Journal of Engineering Applied Sciences and Technology, 2019 \\ Vol. 4, Issue 3, ISSN No. 2455-2143, Pages 20-34 \\ Published Online July 2019 in IJEAST (http://www.ijeast.com)}

[22] Noguet, D., Gautier, M., \& Berg, V. (2011). Advances in opportunistic radio technologies for TVWS. EURASIP Journal on Wireless Communications and Networking, 2011(1), 170.

[23] Farhang-Boroujeny, B. (2011). OFDM versus filter bank multicarrier. IEEE signal processing magazine, 28(3), 92-112.

[24] L. Ping, L. Liu, and W. K. Leung, "A Simple Approach to Near-Optimal Multiuser Detection: Interleave-Division Multiple-Access," Proc. IEEE WCNC 2003, New Orleans, LA, Mar. 2003, pp. 391-96.

[25] V. Vakilianet al., "Universal Filtered MultiCarrier Technique for Wireless Systems Beyond LTE," 9th Int'l.Wksp. Broadband Wireless Access, IEEE GLOBECOM'13, Atlanta, GA, Dec. 2013.

[26] N. Cassiau, D. Kténas, and J.-B. Doré, "Time and FrequencySynchronization for CoMP with FBMC," Proc.ISWCS '13, Ilmenau, Germany, August 2013

[27]G. Wunder, J. Schreck, and P. Jung, "Nearly Doubling the Throughput of Multiuser MIMO Systems Using Codebook Tailored Limited Feedback Protocol," IEEETrans. Wireless Commun., vol. 11, no. 11, 2012, http://www.arxiv.org/pdf/1107.2101, pp. 392131.

[28] J. Schreck, G. Wunder, and P. Jung, "Robust Iterative Interference Alignment for Cellular Networks with Limited Feedback," Int'l. Wksp. Emerging Technologies forLTE-Advanced and Beyond-4G, IEEE GLOBECOM '13, Atlanta, GA, Dec. 2013, http://arxiv.org/abs/1308.6750

[29]R. Irmeret al., "Coordinated Multipoint: Concepts, Performance, and Feld Trial Results," IEEE Commun. Mag., vol. 49, no. 2, Feb. 2011, pp. 102-11.

[30]G. Fettweis, M. Krondorf, and S. Bittner, "GFDM - Generalized Frequency Division Multiplexing," Proc. IEEE $69^{\text {th }}$ VTC Spring, Barcelona, Spain, Apr. 2009, pp. 1-4.

[31]I. Gaspar et al., "Low Complexity GFDM Receiver Based On Sparse Frequency Domain Processing," Proc. $77^{\text {th }}$ IEEE VTC Spring, Dresden, Germany, June 2013.

[32]C. Han et al., "Green Radio: Radio Techniques to Enable Energy Efficient Wireless Networks," IEEE Commun. Mag., vol. 49, no. 6, June 2011, pp. 46-54.

[33]F. Ruseket al., "Scaling Up MIMO: Opportunities and Challenges with Very Large Arrays," IEEE Sig. Proc.Mag., vol. 30, no. 1, Jan. 2013, pp. 40-60.
[34]C.-X. Wang and S. Wu, "Massive MIMO Channel Measurements and Modeling: Advances and Challenges" IEEE Wireless Commun.., submitted for publication

[35] M. D. Renzo et al., "Spatial Modulation for Generalized MIMO: Challenges, Opportunities, and Implementation," Proc. IEEE, vol. 102, no. 1, Jan. 2014, pp. 56-103.

[36] V. Chandrasekhar, J. G. Andrews, and A. Gatherer, "Femtocell networks: a survey," IEEE Communications Magazine, vol. 46, no. 9, pp. 59-67, Sep. 2008.

[37] M. Dohler, R. W. Heath, A. Lozano, C. B. Papadias, and R. A. Valenzuela, "Is the PHY layer dead?" IEEE Communications Magazine, vol. 49, no. 4, pp. 159-165, Apr. 2011.

[38]K. Shen and W. Yu, "Distributed pricing-based user association for downlink heterogeneous cellular networks," IEEE Journal on Sel. Areas in Communications, Sep. 2014.

[39] A. Bedekar and R. Agrawal, "Optimal muting and load balancing for eICIC," in Proc., International Symposium on Modeling \& Optimization in Mobile, Ad Hoc \& Wireless Networks (WiOpt), May 2013, pp. 280-287.42

[40] "Optimal resource allocation in HetNets," in Proc., IEEE Intl. Conf. on Communications, Jun. 2013, pp. 5437-5441.

[41] S. Hanly and P. Whiting, "On the capacity of HetNets," in Proc., Information Theory and its Applications (ITA), Feb. 2014.

[42] J. Lee, Y. Kim, H. Lee, B. L. Ng, D. Mazzarese, J. Liu, W. Xiao, and Y. Zhou, "Coordinated multipoint transmission and reception in LTEadvanced systems," IEEE Communications Magazine, vol. 50, no. 11, pp. 44-50, 2012.

[43] J. Kim, H.-W. Lee, and S. Chong, "Virtual cell beamforming in cooperative networks," IEEE Journal on Sel. Areas in Communications, Sep. 2014.

[44] S. Singh, M. Kulkarni, and J. G. Andrews, "A tractable model for rate in noise limited mmwave cellular networks," in Proc., IEEE Asilomar, Nov. 2014.

[45] T. S. Rappaport, S. Sun, R. Mayzus, H. Zhao, Y. Azar, K. Wang, G. N. Wong, J. K. Schulz, M. Samimi, and F. Gutierrez, "Millimeter wave mobile communications for $5 \mathrm{G}$ cellular: It will work!" IEEE Access, vol. 1, no. 1, pp. 335-349, Aug. 2013.

[46] W. Roh et al., "Millimeter-wave beamforming as an enabling technology for 5G cellular communications: theoretical feasibility and prototype results," IEEE Communications 


\section{International Journal of Engineering Applied Sciences and Technology, 2019 \\ Vol. 4, Issue 3, ISSN No. 2455-2143, Pages 20-34 \\ Published Online July 2019 in IJEAST (http://www.ijeast.com)}

Magazine, vol. 52, no. 2, pp. 106-113, Feb. 2014.

[47] S. Rangan, T. Rappaport, and E. Erkip, "Millimeter-wave cellular wireless networks: Potentials and challenges," Proceedings of the IEEE, vol. 102, no. 3, pp. 366-385, Mar. 2014.

[48] T. S. Rappaport, F. Gutierrez, E. Ben-Dor, J. Murdock, Y. Qiao, and J. I. Tamir, "Broadband millimeter-wave propagation measurements and models using adaptive-beam antennas for outdoor urban cellular communications," IEEE Trans. on Antennas and Propagation, vol. 61, no. 4, pp. 1850-1859, Apr. 2013.

[49] M. Kulkarni, S. Singh, and J. G. Andrews, "Coverage and rate trends in dense urban mmwave cellular networks," in Submitted to IEEE Globecom, Dec. 2014.

[50] T. Bai, R. Vaze, and R. W. Heath, "Analysis of blockage effects on urban cellular networks," Submitted to IEEE Trans. on Wireless Communications, arXiv preprint arXiv:1309.4141, 2013.

[51] T. Bai and R. W. Heath Jr, "Coverage analysis for millimeter wave cellular networks with blockage effects," in Proc., IEEE Global Signal and Information Processing Conference, Dec. 2013.

[52] T. Bai, R. Vaze, and R. W. Heath Jr., "Using random shape theory to model blockage in random cellular networks," in Proc. of Int. Conf. on Signal Processing and Communications (SPCOM), Jul. 2012, pp. $1-5$.

[53] A. Ghosh, T. A. Thomas, M. Cudak, R. Ratasuk, P. Moorut, F. W. Vook, T. Rappaport, J. George R MacCartney, S. Sun, and S. Nie, "Millimeter wave enhanced local area systems: A high data rate approach for future wireless networks," IEEE Journal on Sel. Areas in Communications, Sep. 2014.

[54] M. R. Akdeniz, Y. Liu, S. Sun, S. Rangan, T. S. Rappaport, and E. Erkip, "Millimeter wave channel modeling and cellular capacity evaluation,"

[55] M. Marcus and B. Pattan, "Millimeter wave propagation; spectrum management implications," IEEE Microwave Magazine, vol. 6, no. 2, pp. 54-62, Jun. 2005.

[56]Z. Pi and F. Khan, "An introduction to millimeter-wave mobile broadband systems," IEEE Communications Magazine, vol. 49, no. 6, pp. 101-107, Jun. 2011.

[57]H. Ishii, Y. Kishiyama, and H. Takahashi, "Novel architecture for LTE-B: C-plane/U-plane split and phantom cell concept," in Proc.,
Globecom 2012 Workshop on Emerging Technologies for LTE-A and

B4G, Dec. 2012.

[58] T. Bai and R. W. Heath, "Analysis of millimeter wave cellular networks with overlaid microwave base stations," in Asilomar Conference on Signals, Systems and Computers (ASILOMAR), Pacific Grove, CA, Nov. 2014.

[59] O. E. Ayach, S. Rajagopal, S. Abu-Surra, Z. Pi, and R. W. H. Jr, "Spatially sparse precoding in millimeter wave MIMO systems," to appear, IEEE Trans. on Wireless Communications.

[60] A. Alkhateeb, O. E. Ayach, G. Leus, and R. W. H. Jr, "Channel estimation and hybrid precoding for millimeter wave cellular systemss," Submitted to IEEE Journal of Sel. Topics in Signal Processing, arXiv preprint arXiv:1401.7426, 2014.

[61] J. Hoydis, S. ten Brink, and M. Debbah, "Massive MIMO in the UL/DL of cellular networks: How many antennas do we need?" IEEE Journal on Sel. Areas in Communications, vol. 31, no. 2, pp. 160-171, Feb. 2013.

[62]F. Rusek, D. Persson, B. K. Lau, E. Larsson, T. Marzetta, O. Edfors, and F. Tufvesson, "Scaling up MIMO: Opportunities and challenges with very large arrays," IEEE Signal Processing Magazine, vol. 30, no. 1, pp. 40-60, Jan. 2013.

[63]F. Boccardi, R. W. Heath, A. Lozano, T. L. Marzetta, and P. Popovski, "Five disruptive technology directions for 5

[64]Y. Zeng, R. Zhang, and Z. N. Chen, "Electromagnetic lens-focusing antenna enabled massive MIMO: performance improvement and cost reduction," IEEE Journal on Sel. Areas in Communications, Sep. 2014.

[65] S. Wu, C. Wang, H. Aggoune, M. Alwakeel, and Y. He, "A nonstationary 3D wideband twincluster model for $5 \mathrm{G}$ massive MIMO channels," IEEE Journal on Sel. Areas in Communications, Sep. 2014

[66] 3GPP TSG RAN Plenary No. 58, "Study on 3Dchannel model for elevation beamforming and FD-MIMO studies for LTE,” Dec. 2012.

[67]A. Kammoun, H. Khanfir, Z. Altman, M. Debbah, and M. Kamoun, "Preliminary results on 3D channel modeling: From theory to standardization," IEEE Journal on Sel. Areas in Communications, Sep. 2014.

[68]C. E. Shannon, "A mathematical theory of communication (part 1)," Bell System Tech. Journal, vol. 27, pp. 379-423, 1948.

[69]A. Ghosh, J. Zhang, J. G. Andrews, and R. Muhamed, Fundamentals of LTE. Prentice-Hall, 2010 . 


\section{International Journal of Engineering Applied Sciences and Technology, 2019 \\ Vol. 4, Issue 3, ISSN No. 2455-2143, Pages 20-34 \\ Published Online July 2019 in IJEAST (http://www.ijeast.com)}

[70] S. Hong, M. Sagong, C. Lim, S. Cho, K. Cheun, and K. Yang, "Frequency and quadratureamplitude modulation for downlink cellular OFDMA networks," IEEE Journal on Sel. Areas in Communications, Sep. 2014

[71] N. Cassiau, D. Ktenas, and J.-B. Dore, "Time and frequency synchronization for CoMP with FBMC," in 10th International Symposium on Wireless Communication Systems, Aug 2013, pp. 1-5.

[72] G. Fettweis, M. Krondorf, and S. Bittner, "GFDM - generalized frequency division multiplexing," in Proc., IEEE Veh. Technology Conf., Apr. 2009, pp. 1-4.

[73]R. Datta, D. Panaitopol, and G. Fettweis, "Analysis of cyclostationary GFDM signal properties in flexible cognitive radio," in Proc., Intl. Symposium on Communications and Info. Technol., Oct. 2012, pp. 663-667.

[74] N. Benvenuto, R. Dinis, D. Falconer, and S. Tomasin, "Single carrier modulation with nonlinear frequency domain equalization: An idea whose time has come - again," Proceedings of the IEEE, vol. 98, no. 1, pp. 69-96, Jan 2010.

[75] "Network function virtualisation - an introduction, benefit, enablers, challenges and call for action," white paper, Oct. 2012. [Online]. Available: http://portal.etsi.org/NFV/NFV White Paper.pdf

[76] "Network function virtualisation - network operator perspectives on industry progress," white paper, Oct. 2013. [Online]. Available: http://portal.etsi.org/NFV/NFV White Paper2.pdf

[77] "AT\&T domain 2.0 vision," white paper, Nov. 2013. [Online]. Available: http://att.com

[78] "Software-defined networking, the new norm for networks," Apr. 2012. [Online]. Available: http://www.opennetworking.org

[79]R. Coase, "The federal communications commission," Journal of Law and Economics, vol. 2, no. 1, pp. 1-40, Oct. 1959.

[80] Y. Benkler, "Open wireless vs. licensed spectrum: Evidence from market adoption," Harvard Journal of Law and Technology, vol. 26, no. 1, pp. 71-163, Oct. 2012.165

[81] Cisco, "Visual networking index" white paper at Cisco.com, Feb 2014.

[82] M. Matinmikko, M. Palola, H. Saarnisaari, M. Keikkila, J. Prokkola, T. Kippola, T. Hanninen, M. Jokinen, and S. Yrjola, "Cognitive radio trial environment: First live authorized shared accessbased spectrum sharing demonstration," Proc.,
IEEE Veh. Technology Magazine, vol. 8, no. 3, pp. 30-37, Sep. 2013.

[83] J. Khun-Jush, P. Bender, B. Deschamps, and M. Gundlach, "Licensed shared access as complementary approach to meet spectrum demands: Benefits for next generation cellular systems," ETSI Workshop on Reconfigurable Radio Systems, Cannes, France, pp. 1-7, Dec. 2013.

[84]H. Zhou, R. Berry, M. Honig, and R. Vohra, "Complexity of allocation problems in spectrum markets with interference complementarities," IEEE Journal on Sel. Areas in Communications, vol. 31, no. 3, pp. 489-499, Mar. 2013.

[85] R. Berry, M. Honig, and R. Vohra, "Spectrum markets: Motivation, challenges, and implications," IEEE Communications Magazine, vol. 48, no. 11, pp. 146-155, Nov. 2010.

[86] T. Nguyen, H. Zhou, R. Berry, M. Honig, and R. Vohra, "The impact of additional unlicensed spectrum on wireless services competition," in Proc., IEEE Intl. Symposium on New Frontiers in Dynamic Spectrum Access Networks (DYSPAN), May 2011, pp. 146-155.

[87]H. Zhou, R. Berry, M. Honig, and R. Vohra, "Investment and competition in unlicensed spectrum," in Proc., 46th Conference on Information Sciences and Systems (CISS), Mar. 2012, pp. 1-6.

[88] Blanco, Bego, et al. "Technology pillars in the architecture of future $5 \mathrm{G}$ mobile networks: NFV, MEC and SDN." Computer Standards \& Interfaces 54 (2017): 216-228.

[89] Series, M. "IMT Vision-Framework and overall objectives of the future development of IMT for 2020 and beyond." Recommendation ITU (2015): 2083-0.

[90]5GMF. “ 5G Mobile Communications Systems for 2020 and Beyond.” (2016).

[91] http://www.zdnet.com/article/finland-starting-tobuild-its-first-5g-test-network/

[92] https://www.ericsson.com/en/news/2017/1/ericss on-and-orange-demonstrate-speeds-beyond$10 \mathrm{gbps}$-in-live-5g-field-trial

[93] http://www.huawei.com/en/pressevents/news/2016/11/World-First-5G-LargeScale-Field-Trial

[94] https://newsroom.cisco.com/press-release $\underline{\text { content?articleId }=1844370 \& \text { type }=\text { webcontent }}$ 
International Journal of Engineering Applied Sciences and Technology, 2019

Vol. 4, Issue 3, ISSN No. 2455-2143, Pages 20-34

Published Online July 2019 in IJEAST (http://www.ijeast.com)

[95] http://techblog.comsoc.org/2017/08/30/chinas-

5g-network-trials-announced-commercial-

service-in-2020/

[96] http://www.zte.com.cn/global/about/press-

center/news/201709ma/0929ma1

[97] https://news.samsung.com/global/sktelecom-and-samsung-successfullycompleted-4g-and-5g-network-interworkingtrial-in-seoul

[98] http://www.fujitsu.com/global/about/resourc es/news/press-releases/2017/1107-01.html

[99] https://www.rcrwireless.com/20171129/5g/nokia -elisa-5g-fixed-wireless-access-tag17

[100] http://www.huawei.com/en/pressevents/news/2017/12/NTT-DOCOMO-5GmmWave-Field-Trial-Tokyo

[101] https://economictimes.indiatimes.com/article show $/ 63046414 . \mathrm{cms}$ ?utm source $=$ contentofinter est\&utm_medium=text\&utm_campaign=cppst

[102] https://www.huawei.com/en/pressevents/news/2018/2/first-urban-5G-WirelessHome-CPE-trial

[103] http://www.zdnet.com/article/mwc-2018huawei-and-bt-to-trial-5g/

[104] https://tools.ietf.org/id/5g?maxhits=100\&ke $\mathrm{y}=$ date $\&$ dir $=$ desc

[105] https://www.itu.int/en/ITU-R/studygroups/rsg5/rwp5d/imt-2020/Pages/default.aspx [106] https://www.itu.int/en/ITUD/Regional Presence/CIS/Documents/Events/2017/06_Saint _Petersburg/Presentations/ITU 